\title{
Terminological and conceptual dilemma: strategies and processes as elicited through verbal reports on reading
}

\begin{abstract}
The paper analyses the ways in which the terms processes and strategies are defined within literature reporting verbal protocols on reading. The main argument presented concerns the fact that distinguishing between the two terms in not always based on the same criteria.
\end{abstract}

KEYWORDS: strategies, processes, verbal protocol, verbal report, think aloud, reading.

\section{INTRODUCTION}

This article deals with the ambiguity concerning strategies and processes terms which appear as most fundamental within cognitive studies, but which are still not clearly and definitely defined. The analysis presented is narrowed to the field of verbal reporting, and even more specifically, to verbal protocols on reading. The reason for doing so is that within the literature dealing with verbal protocols on reading there appears to be no 'convention' for the use of the above mentioned terms. At the same time, this 'lack of convention' is most often ignored, and as if taken for granted. It seems that researchers simply got used to the terminological variety, and, at least at certain times, stopped being bothered with the differences in the naming or 'tagging' of similar phenomena. This, in a sense, represents a prudent approach, as the differences in the names used should not be considered as impeding comparisons across research studies. On the other hand, though, the differences may appear as confusing. I would like to emphasize that the discussion presented in this paper is not supposed to give any definite conclusions concerning how to name cognitive phenomena, as this would be hardly possible. It is rather meant to point to terminological variety concerning verbal report data, and to the need to recognize this variety. 
In the beginning of this article it is also important to notice that the think aloud verbal protocol, mainly referred to in this article, is a relatively new method of collecting cognitive data. It consists in asking respondents to verbalize their thoughts while they work on a particular task. The method was first used in the problem solving research (Newell and Simon 1972), and only later was adopted in other areas, also in the field of researching reading. First users of think aloud on reading (for example Olshavsky 1976-1977) drew analogies between the processes of reading and problem solving, and referred directly to Newell and Simon's methodology. About one decade later, there appeared the work of Ericsson and Simon (1984), who thoroughly reviewed the up-to-then collected verbal report data and provided it with theoretical framework. This volume, reissued in 1993, continues to be the main reference for researchers working with the use of think aloud and other forms of verbal report. Yet, as the work of Ericsson and Simon is to a large extent theoretical, researchers sometimes prefer to refer to newer and more practically-minded books, for example the one of Green (2009). As both the works offer methodological guidelines, they are considered influential as far as subsequent verbal report studies are concerned. Thus, this paper will necessarily refer to both the works. It will also look at the way researchers who draw from the work of Ericsson and Simon distinguish between the terms strategies and processes.

I believe a good starting point for the analysis that evolves further in the paper will be quoting some of the definitions used. So, for example, it is common, within information processing theory, to distinguish between processes and strategies merely basing on how conscious the phenomena are. "What may distinguish strategies from skills and other processes is the level of awareness and deliberation on the processes, rather than the nature of the processes per se" (Phakiti 2008: 238). According to this definition, strategies are conscious, though, they may 'loose their significance as strategies' and become processes through repetitive practice leading to automatization. "If the learners cannot identify any strategy [...] as it is unconscious, then the behaviour would simply be referred to as a common process, not a strategy." (Phakiti 2003: 28). "If strategies become so automatic that learners are no longer conscious of employing them and they cannot be accessible for description, they lose their significance as strategies." (Phakiti 2003: 28). This perspective of looking at strategies is adopted by Cohen and Upton (2007), working within the field of verbal reporting. The authors state that "while processes are general, subconscious or unconscious, and more automatic, strategies are subject to control, more intentional, and used to act upon the processes" (Cohen and Upton 2007: 11). Strategies then are phenomena of which respondents "are conscious [...], at least to some degree" (Cohen and Upton 2007: 211). 
The analysis that follows in this paper is mainly concerned with the fact that Ericsson and Simon' work, and consequently also Green's work (being a simplified and more practically-minded re-issuing of the classic) do not frame the distinction between strategies and processes in the ways presented above. The more specific issues addressed in the paper concern the facts that:

a) researchers working with verbal reports happen to refer to the work of Ericsson and Simon, and still define the term strategy in a way which differs from the sense given to it by these authors, and

b) researchers working within the field of verbal reports on reading are not unanimous in the way they term supposedly similar cognitive phenomena.

\section{ERICSSON AND SIMON'S PERSPECTIVE ON PROCESSES AND STRATEGIES AS REFLECTED THROUGH VERBAL REPORTS}

When referring to the level of consciousness of cognitive phenomena, and consequently to how likely the phenomena are to get reflected in verbal reports, Ericsson and Simon use the names of conscious and not conscious (automatic) processes. They notice, at the same time, that automatic processes are not revealed through think aloud protocols, and that through practice certain behaviours become automatic, and thus may disappear from subsequent verbal reports (Ericsson and Simon 1993: 90).

Our model assumes only information in focal attention can be verbalized. In most theories of the structure of the human information processing system a distinction is made between fast, automatic processes that are not necessarily conscious (and which are often thought to proceed in parallel) and the slow serial processes that are executed under cognitive control [...]. In our discussion, we will adopt this distinction. We will also assume that with increase in experience with a task, the same process may move from cognitively controlled to automatic status, so that what is available for verbalization to the novice may be unavailable to the expert. (Ericsson and Simon 1993: 90).

So, the distinction referring to consciousness of mental activity concerns phenomena denoted as conscious processes and unconscious (automatic) processes. The term strategy is not used strictly with reference to this distinction. What, as Ericsson and Simon explain, is most often coded basing on verbal report data are structures of knowledge pointing to certain (consciously used) processes (Ericsson and Simon 1993: 310). These processes, when inferred from verbal protocol data, form the basis for the discovery of larger patterns called strategies (Ericsson and Simon 1993: 350). So strategies, as 
described by Ericsson and Simon, are ways or methods of dealing with a problem or task, "«methods of attack» on reasoning problems", "general mode of solving problems" (Ericsson and Simon 1993: 202). Strategy is also referred to as a global "plan or system" used for problem solving (Ericsson and Simon 1993: 203, 341). Ericsson and Simon make it clear that distinguishing between what constitutes a strategy and what is a process is not a matter of distinguishing between their conscious or unconscious realizations. After all, verbal protocols are described as displaying only conscious processes. Thus, strategies, which are inferred from verbal report data, will necessarily have to be considered conscious as well. What according to the authors differentiates the two concepts discussed is rather their relative hierarchy. Strategies are clearly defined as sequences of processes, thus are higher in hierarchy: they are more global and refer to larger parts of verbalizations, sometimes, as the authors admit, to the entire protocol. They are deliberate, planned and clearly sequential in nature, denoting more elaborate actions. At the same time, as the authors admit, it is possible to code verbal protocol directly according to strategies used, though such coding will have to rely on larger segments of the verbalization (up to entire protocols) and will be more difficult to realize. It seems that the distinction between encoding verbalizations with reference to processes and with reference to strategies relates in fact to what might be called working on microunits and macro-units of the protocol:

During the segmentation, units should be defined that are large enough that all information for making an encoding decision is contained in a single segment. For certain encoding decisions, like assessing strategies, this may mean that the entire protocol is a unit. (Ericsson and Simon 1993: 290).

Elsewhere, the authors (1993: 305) refer to the term strategy by mentioning "both the sequence in which information will be addressed, and the decisions that will be reached". So the term strategy implies a sequence of planned operations.

Green, who mostly restates what Simon and Ericsson said, conceptualizes strategy in a similar way, as "a sequence of processes":

It is important to consider how strategies are inferred from verbal protocols, and how they are represented by different coding schemes. An individual strategy can be considered as a unique sequence of processes. Thus, strategies are inferred from verbal protocols by examining the protocols for particular sequences or patterns of processes. (Green 2009: 71).

Green (2009: 74) only marginally mentions the issue of hierarchical coding of micro- and macro-units of verbalization. Normally, as the author as- 
sumes, protocol segments will be coded according to the processes they reflect. She also warns that each segment "should correspond to an individual process" (Green 2009: 78). In case of reading, the processes may involve particular instances of (for example):

- detailed reading,

- re-reading materials,

- focusing (i.e. re-reading something immediately),

- paraphrasing materials,

- skimming or scanning the text,

- summarizing content,

- interpreting text,

- assessing some aspects of the information. (Green 2009: 82).

On the other hand, strategies used by respondents working on a sample reading task were described as follows:

We begin by considering Student 1 . From the coded segments, this student appears to go through a cycle of reading followed by re-reading sections of the passage. At segment 006 the student 'focuses', perhaps on a particular word or phrase, and then retrieves the meaning of that particular word or phrase. This could suggest an initial failure to understand and then retrieval of the appropriate meaning. The student then reads the question, re-reads the question and then re-reads some text. Further cycles of re-reading the question and the text then ensue before the question is answered.

Student 2 approaches the task differently. Student 2 reads a section of text, focuses on a phrase or word and then continues to read. The cycle is repeated until the passage is read. Responding to the first question of the text, the student reads the question, focuses on a particular word or phrase and then searches the text for that word or phrase. The question is then answered. (Green 2009: 72).

What the two extracts demonstrate, as Green explains, is that the respondents use similar processes (of reading, re-reading, and focusing), yet they organize them differently, which stands for using different strategies: "although both students use similar processes, the pattern of processing, and thus the strategies used, differ" (Green 2009: 72). Particular instances of behaviours, coded for example as scanning, focusing or re-reading (2009: 71-72), are not considered strategies.

\section{REFERRING TO (AND DIVERGING FROM) ERICSSON AND SIMON'S METHODOLOGY}

As was mentioned above, researchers working with verbal reports happen to relate the methodology they use to the work of Ericsson and Simon or of Green, and still to use the term strategy in a way which differs from the 
sense given to it by these authors. This sometimes takes place without any notice of the differences in the meaning of the terms used. And so for example, Cohen and Upton (2007: 212) make straight and very explicit reference to Green. They also refer to Ericsson and Simon (Cohen and Upton, 2007: 219). Yet, they do not provide any explanation for the fact that the way they define strategies differs from Ericsson and Simon's as well as from Green's definition. For Cohen and Upton, the distinction between strategies and processes concerns the level of consciousness: strategies, due to being conscious, are likely to get reflected in verbal protocols, while processes are not. There is no presupposition that strategies must consist of a sequence of actions, though there is no denial of it, either. The actions coded by Cohen and Upton as strategies are of various complexity: some of them reflect a single move, like for example:

- identifying an unknown word or phrase,

- considering prior knowledge of the topic,

- looking for sentences that convey the main ideas. (Cohen and Upton, 2007: 220).

Others contain a time related sequence of moves, for example:

- reading the question and then reading the passage/portion to look for clues to the answer, either before or while considering options,

- predicting or producing own answer after reading the portion of the text referred to by the question,

- predicting or producing own answer after reading the question and then looking at the options (before returning to text). (Cohen and Upton 2007: 221).

All the strategies implying a sequence of moves belong to the category denoted by the authors as test management strategies, and are concerned with the separate components of the task (the question, the reading passage and options). Cohen and Upton (2007) do not bother about the fact that some of the categories they code are as if internally simpler, in the sense that they refer to just one move, and others are more complex, in the sense that they refer to a series of moves. At the same time, the protocol is segmented and coded directly according to the strategies it reflects.

Bråten and Strømsø also use think aloud on reading and refer to Simon and Ericsson (Bråten and Strømsø 2003: 204). The authors clearly prefer using the term strategic processing for what they code, though they sometimes also talk about strategies (Bråten and Strømsø 2003: 195, 212). In this case, the meaning of the term strategy again departs from the one intended by Ericsson and Simon. In Bråten and Strømsø's report, strategies include both single instances of actions: for example memorization (repeating, paraphras- 
ing), elaboration (linking text to other sources of knowledge), monitoring comprehension (comments admitting having understood something), as well as more elaborate actions, implying some sequence of steps taken, for example monitoring problem-detection and problem solving,

coded as present if the reader provided evidence of awareness of lack of comprehension $[\ldots]$ and, as a consequence, tried to regulate or repair his or her comprehension by a) rereading $[\ldots]$, b) searching for clarifying information elsewhere in the text $[\ldots], c)$ utilizing prior knowledge $[\ldots], \mathrm{d}$ ) searching for clarifying information in other sources [...], e) skipping the problem and reading on [...]. (Bråten and Strømsø 2003: 206-207).

Jiménez, García and Pearson (1996), as well as Lau (2006) also relate the methodology they use to Ericsson and Simon, while using the term strategies with reference to instances of 'single-action' behaviours, like for example paraphrasing, rereading, or confirming. In fact, it would be possible to enumerate many other authors choosing to use the term strategy with reference to nonsequential data collected directly from micro-level verbal report segments (for example Block, 1986; Kletzien, 1991; Davis and Bistodeau, 1993; Yau, 2005). Olshavsky (1976-1977), working with verbal reports on reading yet before the publication of Ericsson and Simon's work, also used the name strategies for encoding single demonstrations of non-sequential moves derived straightforwardly from the micro-units of verbal report.

It should be admitted, though, that researchers are not unanimous in the way they refer to the encodings of reading report micro-units (which are typically instances of rereading, paraphrasing, repeating, inference, predicting etc.). Sometimes researchers seem to avoid using the term strategy. And so for example Pressley and Hilden (2004) choose to talk about "conscious processes of reading", Kendeou, Muis and Fulton (2011: 3) talk about "strategic and automatic processes", and Scott (2008: 302, 308) about "text processing behaviours". It must be admitted, at the same time, that verbal report literature reflects uncertainty and sometimes even confusion regarding the terms discussed. The above mentioned paper of Scott (2008), for example, generally not using the name strategy with reference to verbal protocol data, at some point states that "since the reader reports only the contents of the working memory, [...] responses may not accurately reflect all processing [...]. For example, strategies that are applied automatically may not be verbalized." (Scott 2008: 294). This statement clearly ignores that fact that strategies are most often considered to be consciously applied. At the same time, it may be considered as exemplifying the inconsistencies regarding the use of the two terms discussed. 


\section{CONCLUSION}

The here presented paper might be perceived as restating what has been widely acknowledged, namely that "researchers do not use terms like process, [and] strategy [...] consistently. Sometimes they use them as synonyms for general mental operations, but sometimes they use them to differentiate operations involved in language processing" (Ellis, 1990: 166).

Yet, as I believe, several points made here should be considered more specific and likely to stimulate further reflection. Firstly, the point that should be considered important is that verbal report 'gurus' frame the concept of strategy, especially as it is used in reading, quite differently from the way many verbal protocol practitioners tend to do it. This might suggest a kind of discomfort with the way the original framing of the term relates to its practical uses. Moreover, Olshavsky (1976-1977), pioneering the work on verbal protocols in reading, also used to define strategies in a way which was not consistent with the norm introduced later by Ericsson and Simon.

The second important point is that the way Ericsson and Simon define the concept of strategy is still largely uncertain and vague, as supposedly, depending on how long and elaborate a particular task is, the same kind of behaviour (for example paraphrasing) could be differently classified. Whether the same action will be called a process or a strategy will depend on how global it appears to be with reference to the whole task. In case of shortly defined reading tasks, mere paraphrase could be in fact considered a strategy. Thus, specific actions performed while reading, for example inferencing the meaning of words, paraphrasing, or interpreting should not in fact be strictly designated as either processes or strategies. The way they are classified has to depend on the nature and complexity of the task, and on how global, when compared with the totality of the task, the particular behaviours appear. At the same time, it can be observed that the term process, being more general, appears as less problematic.

Finally, I must admit I believe it is important that the differences in the terminology used are acknowledged, even by taking a mere notice of them. Even if the way particular phenomena are named does not really change the cognitive findings reported in particular research studies, the terminological differences should be recognized for the sake of clarity and methodological conscientiousness.

\section{REFERENCES}

Block, E., 1986. The comprehension strategies of second language readers. In: TESOL Quarterly 20/3, 463-494. 
Bråten, I. / Strømsø, H.I., 2003. A longitudinal think-aloud study of spontaneous strategic processing during the reading of multiple expository texts. In: Reading and Writing: An Interdisciplinary Journal 16/3, 195-218.

Cohen, A.D. / Upton, T.A., 2007. 'I want to go back to the text': response strategies on the reading subtest of the new TOEFL. In: Language Testing 24/2, 209-250.

Davis, J.N. / Bistodeau, L., 1993. How do L1 and L2 reading differ? Evidence from think aloud protocols. In: The Modern Language Journal 77/4, 459-472.

Ellis, R., 1990. Understanding second language acquisition. Oxford: Oxford University Press.

Ericsson, K.A. / Simon, H.A., 1993. Protocol analysis. Verbal reports as data. Cambridge, MA: MIT Press.

Green, A. 2009., Verbal protocol analysis in language testing research. New York: Cambridge University Press.

Jiménez, R.T. / García, G.E. / Pearson, P.D., 1996. The reading strategies of bilingual Latina/o students who are successful English readers: opportunities and obstacles. In: Reading Research Quarterly 31/1, 90-112.

Kendeou, P. / Muis, K.R. / Fulton, S., 2011. Reader and text factors in reading comprehension processes. In: Journal of Research in Reading 34, 1-19.

Kletzien, S.B., 1991. Strategy use by good and poor comprehenders reading expository text of differing levels. In: Reading Research Quarterly 26/1, 67-86.

Lau, K.L., 2006. Reading strategy use between Chinese good and poor readers: a think-aloud study. In: Journal of Research in Reading 29/4, 383-399.

Newell, A. / Simon, H.A., 1972. Human problem solving. Englewood Cliffs, NJ: Prentice-Hall.

Olshavsky, J.E., 1976-77. Reading as problem solving: an investigation of strategies. In: Reading Research Quarterly 12/4, 654-674.

Phakiti, A., 2003. A closer look at the relationship of cognitive and metacognitive strategy use to EFL reading achievement test performance. In: Language Testing 20/1, 26-56.

Phakiti, A., 2008. Construct validation of Bachman and Palmer's (1996) strategic competence model over time in EFL reading tests. In: Language Testing 25 /2, 237-272.

Pressley, M. / Hilden, K., 2004. Verbal protocols of reading. In: Duke, N.K. / Mallette, M.H. (eds.), Literary research methodologies. New York: The Guilford Press, 308-321.

Scott, D.B. 2008. Assessing text processing: a comparison of four methods. In: Journal of Literacy Research 40/3, 290-316.

Yau, J.C. 2005., Two Mandarin readers in Taiwan: characteristics of children with higher and lower reading proficiency levels. In: Journal of Research in Reading 28/2, 108-124. 
